\title{
MODEL-BASED CONSTRUCTION WORK ANALYSIS CONSIDERING PROCESS-RELATED HAZARDS
}

\author{
Jürgen Melzner \\ Sebastian Hollermann \\ Silvia Kirchner \\ Hans-Joachim Bargstädt \\ Institute for Construction Engineering and Management \\ Bauhaus-Universität Weimar \\ Marienstraße 7A \\ 99432 Weimar, GERMANY
}

\begin{abstract}
The identification of job hazards, before they actually occur, is a challenge for the construction work planner as well as for the safety and health coordinator. The high-risk construction sector records the highest number of accidents among different industry sectors. In most cases, safety planning is purely based on checklists and manual description, which are not closely related to the actual and specific construction object. Modern technologies, such as Building Information Modeling (BIM), are offering an object-oriented planning approach toward a project's lifecycle. This paper presents a research-in-progress project, where the BIM technology has been used to identify object-oriented and process-oriented job safety hazards. Here, the necessary construction processes will be derived from the "to build"-objects in the model. The proposed framework would be able to detect a safety hazard during the early phases of design and planning processes. The scope of research in this paper is limited to safety hazards in solid construction.
\end{abstract}

\section{INTRODUCTION}

The German Occupational Safety Act (ArbSchG $\S 1$ Abs. 1) states that: "[...] safety and health of employees at work need to be secured and improved by the means of protective measures". Therefore, a job hazard analysis (JHA) is useful for detecting hazards and risks present in the daily work at a construction site (U.S. Department of Labor 2002). This paper is concerned with such an analysis, where the implementation of theoretical input will be integrated into a 3D building model. Its aim is to organize the risks in such a manner that they could be associated to a building element in the building information model.

In Germany, more than 100 construction workers die every year at work. This shows that safety concerns have still remained a problem in the construction business. Safety planning in construction is a challenging task because of the large number of parties involved, the constantly changing conditions and the complexity of construction. The nature of construction projects are defined by separate stages of the planning process. It leads to unequal information distribution among the involved work planners. An objective evaluation of the safety planning methods regarding qualitative and quantitative factors could be significantly improved by application of innovative and integrated safety planning tools. Major safety hazards can be identified by reviewing the job accident report. This set of identified hazards constitutes the knowledge base. A thorough review of the detailed report on job accidents forms the basis for linking together objects, processes and accidents. This paper contributes to the process-driven job hazard analysis, with its implementation into the BIM. It also contributes to improvement of safety conditions at construction sites. 


\section{MOTIVATION}

In Germany, the construction sector has remained one of the leading industries in occupational accidents during the last two decades, considering the relevant statistics across different industries (DGUV 2010). Between 1995 and 2005, there was a rapid fall in both fatal and non-fatal occupational accident rates (Figure 1). The current rate of occupational accidents corresponds to less than one third of the previous rate in 1995. Although this signifies a declining trend, it is still necessary to further improve and increase safety at construction sites. A latest review of hazard analysis and safety planning indicates a marked lack of an integrated planning tool that would combine safety regulations and a particular project. The literature indicates that 2D drawings are still commonly used for many building projects. All data and correlations between the building components are evaluated manually and text-based check-lists are used
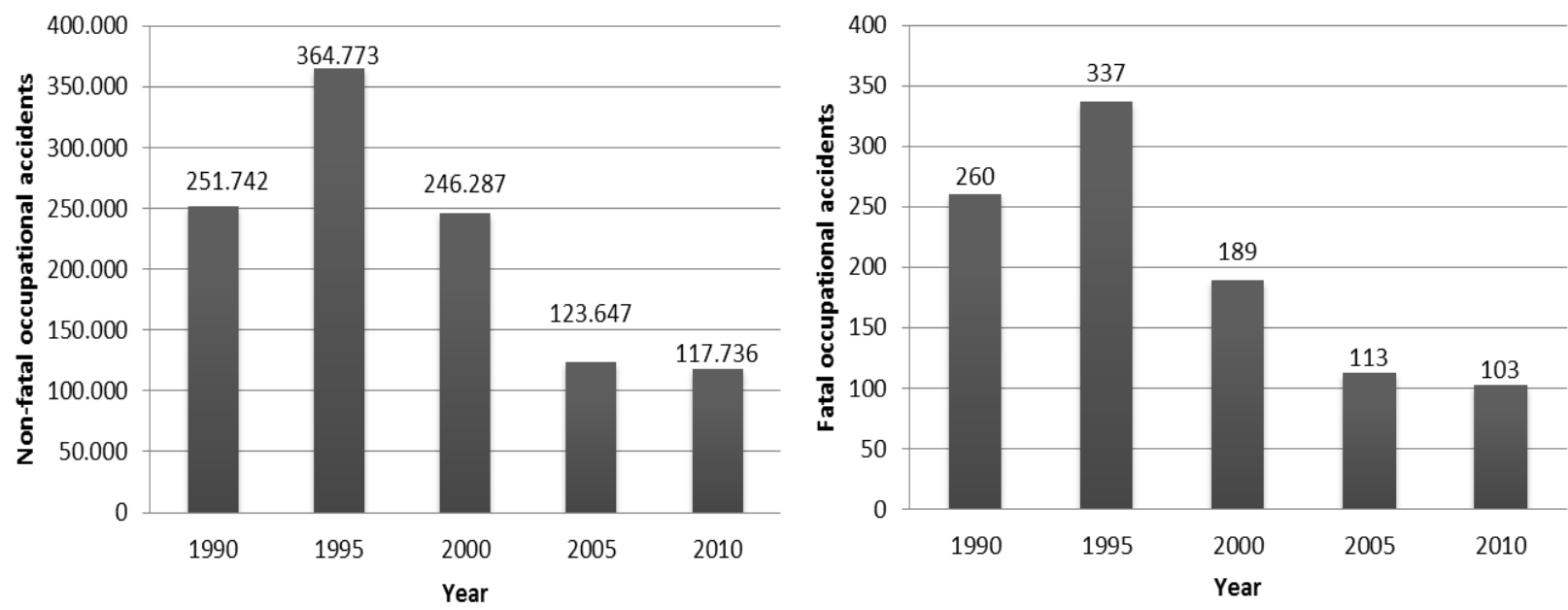

Figure 1: Non-fatal occupational accident rates (left) and fatal occupational accident rates (right) in German construction industry.

\section{BACKGROUND}

\subsection{Job Hazard Analysis}

As mentioned before, safety planning in the construction industry has to improve across the globe (Melzner et al. 2012b). To achieve this, all those responsible for monitoring occupational safety and health ought to carry out advisory and supporting functions to ensure safety for the client, who still remains the main responsible person for a construction project. Rozenfeld et al. (2010) proposed a method called 'Construction Job Safety Analysis' (CJSA). The CJSA method is based on the traditional JSA procedure to safety planning in manufacturing. The CJSA generates a knowledge-base describing all possible lossof-control events and assessment of the probability of occurrence for each event identified in construction.

Safety measurements can be implemented successfully with cooperation of all actors, including construction workers. The implementation of safety measurements, e.g. guard rails, personal protective equipment and coverings, constitutes the next to last step in a hazard analysis, as displayed in Figure 2. 
Melzner, Hollermann, Kirchner, and Bargstädt

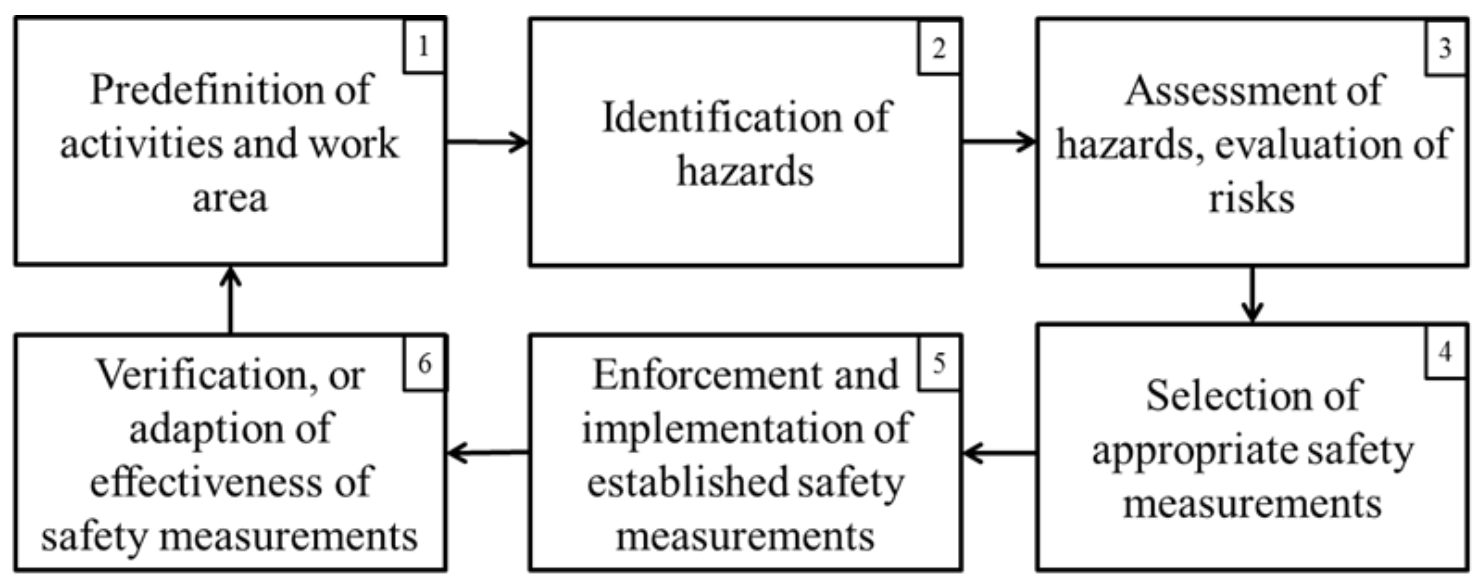

Figure 2: Process of hazard analysis.

\subsection{BIM-based Safety Applications}

This paper examines the first three steps of a hazard analysis, as shown in Figure 2. The results will be implemented in a Building Information Model (BIM). The Associated General Contractors of America (AGC) describes BIM as a data-rich, object-oriented, intelligent and parametric digital representation of a facility (AGC 2010). Furthermore, the BIM processes are about virtual models that make it possible to share information throughout the entire building industry. This variety of the BIM applications paves the way for numerous studies. Support construction management in the early planning phase of Building Information Modeling (BIM) has been acknowledged as an appropriate tool (Hartmann et al. 2008). The gap between the construction process and the health and safety issues can be reduced by the use of Building Information Models through the integration of safety requirements into the software (Sulankivi et al. 2010).

\subsubsection{Manual Tools for Improving Safety Planning}

The so-called "Design-for-Safety" (DfS) tools consider safety aspects during the planning phase to support the cooperation of all participants in terms of safety assessment. The Design for Construction Safety Tool Box, developed by Gambatese et al. (1997), is a software tool to assist designers to eliminate construction site hazards in the checklist format. The database behind the toolbox links the hazard information to particular construction activities. However, there is no direct link between drawings or objects in the building models. Cooke et al. (2008) developed a tool, ToolSHeD, for safety and health in design. It provides an internet-based interactive risk assessment regarding specific construction activities and materials, to support designers to integrate the OHS risk management into the design process. The application is limited to design-related hazards, which are linked to falls from height during maintenance work on building rooftops. A further approach in this field is the Australian Construction Hazard Assessment Implication Review (CHAIR) Tool. It focuses on the documentation of a structured review process by using prompts. The CHAIR Tool provides structured guides to detect safety risks in construction, demolition and maintenance work (WorkCover 2001).

\subsubsection{Visualization Possibilities and Their Potential for Safety Improvement}

Case studies show the advantages of visualization tools for construction safety assessment and communication (Hecker et al., 2004). The possibility of visualizing the safety equipment has significant advantages. For example, a case study conducted by Melzner et al. (2012b) highlights the differences in ap- 


\section{Melzner, Hollermann, Kirchner, and Bargstädt}

plying fall protection regulations in both the both Germany and the United States on a high-rise building project.

$3 \mathrm{D}$ visualization allows the user to analyze and investigate the future construction site in a virtual environment. Potentially hazardous situations could be easily identified and communicated within a 3D model. For example, Sulankivi et al. (2009) used 3D visualization to check the crane reach and capability. This model helps the site layout planner to evaluate the associated risks, in case of load fall of the crane.

Kim and Ahn (2011) proposed a method for temporary facility planning of a construction project by using BIM. According to them, many accidents take place because of incorrectly positioned scaffolding. Using ArchiCAD and Google SketchUP, a 3D model was created which allows visual representation of objects and structure of those exact positions.

Hadikusumo and Rowlinson (2002) proposed a design-for-safety-process (DFSP) tool that would enable a user to do a walk-through the virtual project. It allows to identify safety hazards linked to construction components as well as to propose accident precautions needed to prevent potential accidents. This tool is based on the captured empirical knowledge of safety engineers about construction safety hazards and the required safety measures. Most of the available tools and methods are primarily used for modeling and visualization of safety facilities. However, the available tools provide no assessment of identified risks and alternative solutions.

\subsubsection{Automatic Construction Safety Analysis}

Further developments in the field of IT-based safety support systems lead to automatic construction safety analysis based on object-oriented building models. Benjaoran and Bhokha (2010) described an integrated system for safety and construction management by using the 4D CAD model. They developed a rulebased system to analyze and detect automatically working-at-height hazards and to indicate necessary safety requirements. The developed prototype identifies working-at-height hazards, according to the current status of the construction project.

Qi et al. (2011) developed a tool, Construction Safety Checking System, to check model elements based on a set of pre-defined safety rules. A user needs to select a specific set of rules, which will be checked against the building model. This tool supports architects during the design phase through minimization of safety hazards by providing design alternatives, in case a hazard is identified.

Another recent tool for the automatic construction safety analysis is the application of an automated safety rule checking algorithm to BIM, with the objective to improve safety on construction sites regarding fall-related hazards. The rule checking process developed by Zhang et al. (2013) consists of four major stages: 1) rule interpretation, 2) building model preparation, 3) rule execution and 4) report checking results. This research focuses on an automated generation of fall protection systems, based on objectoriented building models.

Other researchers have explored the use of BIM for safety planning at construction sites. However, most of these researches focus on visualization and communication. It is only recently that they have turned to the object-orientated job hazards analysis. The literature indicates that the use of a digital building information model offers several ways to improve construction safety. However, the integration of safety planning in a digital building model is still uncommon and relatively complicated.

\section{RESEARCH METHODOLOGY}

The first step in this approach is the identification of focal points of occupational accidents in the construction industry. The focal points are derived from earlier records of research projects at the Institute for Construction Engineering and Management at Bauhaus-University Weimar (Röbenack and Nowak 1993, Schüler 2001). They analyzed 37,765 accident reports to probe how, why and when the accidents occurred. The accidents are analyzed on the frequency distributions of the same occurrence ranges, so that the relative frequency of those accidents can be derived. Finally, the identified hazards and risks will be 
assigned to a building element type in a database. This will provide us in the much needed framework. By applying this system, the knowledge base will be checked against the building elements of the building model (Figure 3). The results can be seen in the software prototype.

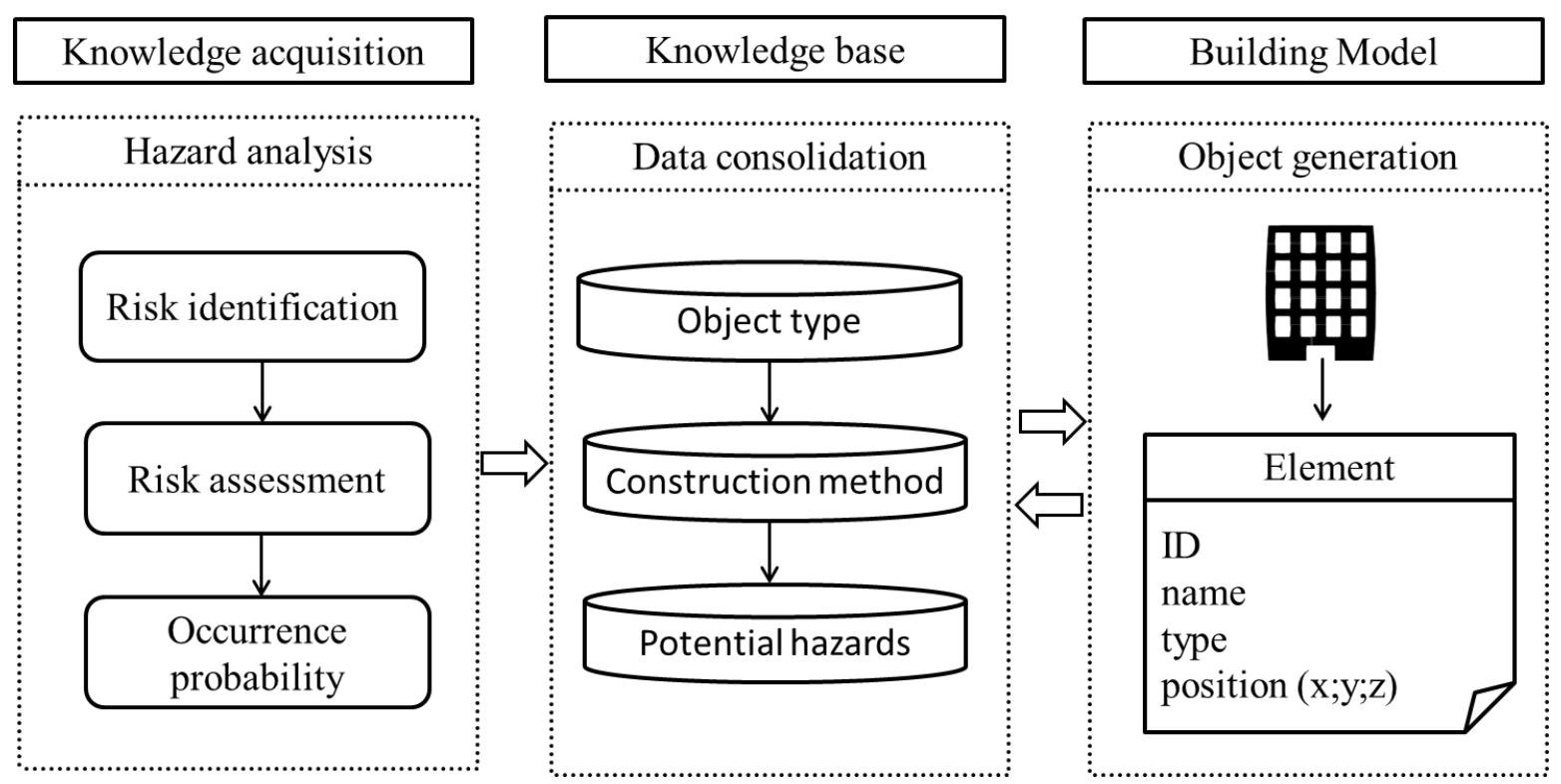

Figure 3: Framework for the knowledge-based system.

\section{EXECUTION OF HAZARD ANALYSIS AND RESULTS}

In this research, the construction processes belonging to the four main categories are considered. The different construction processes, which are relevant for building construction projects, are allocated to the construction methods (Figure 4).
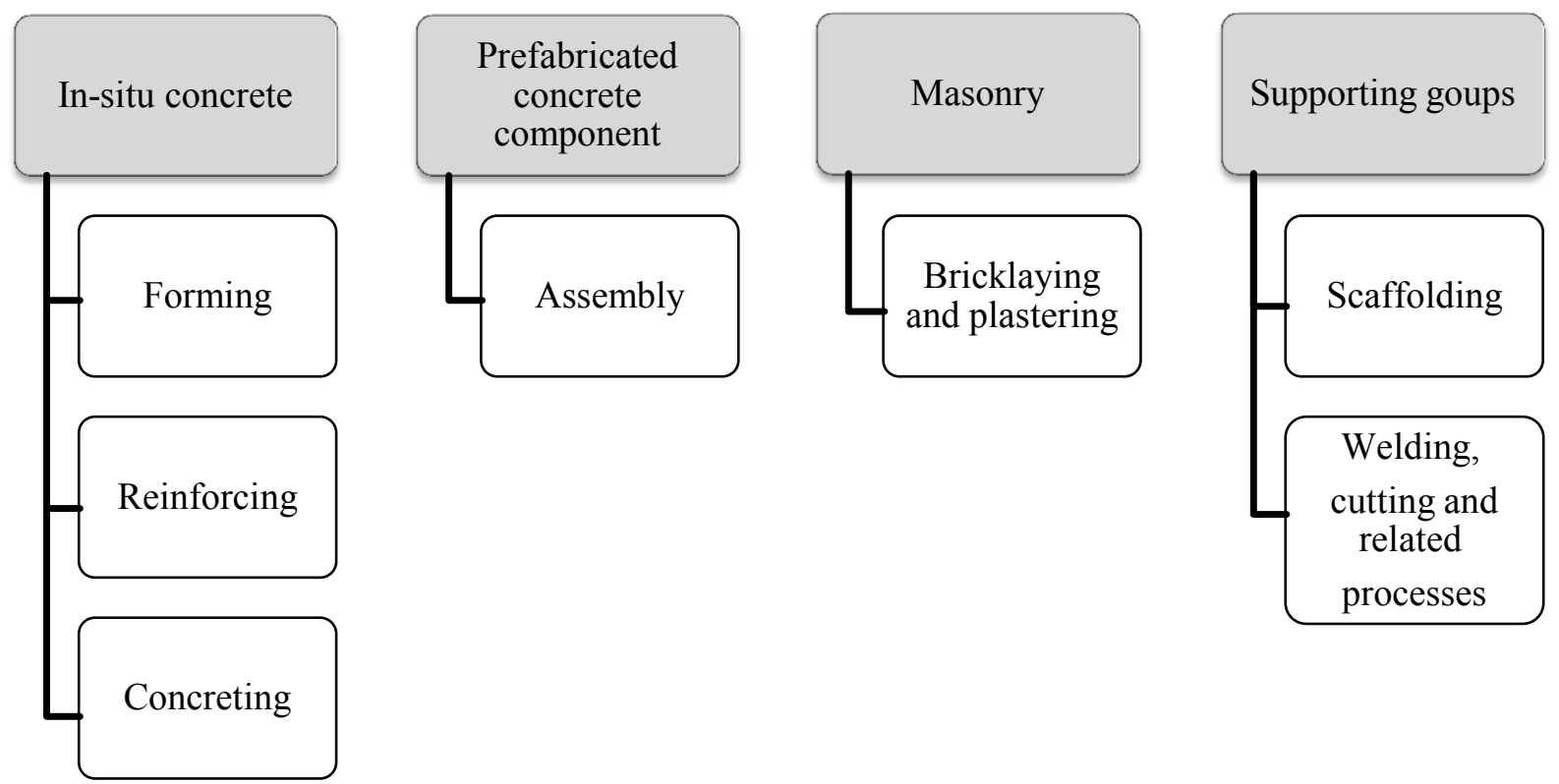

Figure 4: Construction methods and their related processes. 
First, the statistics of occupational accidents are analyzed for identifying dangerous situations and work places during construction work. The chosen categories for the hazard analysis are:

(1) risks caused by the construction method,

(2) hazards caused by the building geometry, and

(3) hazards caused by the construction environment.

Risks caused by the construction method are identified from former accident assessments in the construction industry done by Röbenack and Nowak (1993) and Schüler (2001). They investigated a large number of different occupational accidents, categorized them into different event areas and assigned them to different construction processes (Table 1). The table shows the percentage of occupational accidents in the different event areas (EA) and process that are assigned to the accident (PA) in the three periods of time.

Table 1: Occupational accidents during assembly process (source: Röbenack and Nowak 1993 and Schüler 2001).

Percentage of occupational accidents

\begin{tabular}{|c|c|c|c|c|c|}
\hline & Event areas & $\begin{array}{c}1970-77 \\
x_{1}\end{array}$ & $\begin{array}{c}1983-88 \\
\mathrm{X}_{2}\end{array}$ & $\begin{array}{c}1992-97 \\
x_{3}\end{array}$ & $\begin{array}{l}\text { arithmetic } \\
\text { average }\end{array}$ \\
\hline $\mathbf{A}$ & 1. Pre-assembly & 2,09 & $\mathbf{0 , 8 1}$ & 1,93 & 1,16 \\
\hline PA & 1.1 Laying out pre-fabricated parts & 0,92 & 0,00 & 1,36 & 0,76 \\
\hline PA & 1.3 Fall of unsteady positioned elements & 0,17 & 0,00 & 0,45 & 0,21 \\
\hline EA & 2. Mechanized assembly & $\mathbf{2 0 , 0 0}$ & 15,74 & 33,3 & 23,01 \\
\hline PA & $\begin{array}{l}\text { 2.1. Injury by using of temporary elements by } \\
\text { oscillating movements }\end{array}$ & 0,75 & 0,81 & 0,34 & 0,63 \\
\hline PA & $\begin{array}{l}\text { 2.5. Falling of assembled objects during con- } \\
\text { struction }\end{array}$ & 2,09 & 0,81 & 1,93 & 1,61 \\
\hline $\mathrm{PA}$ & 2.11 Injury by hammering, metal fragments & 1,76 & 1,21 & 7,50 & 3,49 \\
\hline
\end{tabular}

The event areas are mainly divided into four basic categories: (1) different event areas (EA), e.g. preassembly, mechanized assembly and manual assembly; (2) workplace conditions; (3) transport, handling and storage processes; and (4) other factors and their sub-categories. For instance, laying out prefabricated parts, insertion of tendons in pre-stressed concrete girders and falling off unsteady positioned elements are the sub-categories assigned to the basic pre-assembly category. Therefore, the sub-categories are equal to hazard situations.

By integrating the probability of occurrence (PO), which is the average value of all three time series from Table 1 of a process of accident (PA) in relation to a process of accident with the highest percentage of occupational accidents in an event area, the hazards become assessed risks as seen is Equation (1): 


$$
P O_{P A}=\frac{\frac{1}{n} \sum_{i=1}^{n} x_{i} * 100 \%}{\left(\frac{1}{n} \sum_{i=1}^{n} x_{i}\right)_{\max }}
$$

where

PO $\quad$... probability of occurrence,

PA $\quad \ldots$ process of accident,

$x_{i} \quad \ldots$ percentage of occupational accidents per period of time, and

$\frac{1}{n} \sum_{i=1}^{n} x_{i} \quad \ldots$ arithmetic average.

The risk levels are low for $\leq 33 \%$, middle for $\leq 67 \%$ and high for $>67 \%$ probability of occurrence (Table 2).

Table 2: Legend for the probability of occurrence (PO).

\begin{tabular}{ccc}
\hline$P O_{P A}$ & & Symbol \\
\hline$\leq 33 \%$ & low & + \\
$\leq 67 \%$ & middle & ++ \\
$>67 \%$ & high & +++ \\
\hline
\end{tabular}

For further use, the original data from Table 1 needs to be restructured to weight the risk levels in the three categories. The result can be seen in Table 3.

Table 3: Extract from the new generated table of risks by assembly processes.

\begin{tabular}{lc}
\hline Impact and event & Probability of occurrence \\
\hline 1. Pre-assembly & +++ \\
\hline 1.1 Laying out pre-fabricated parts & + \\
\hline 1.3 Fall of unsteady positioned elements & + \\
\hline $\begin{array}{l}\text { 2. Mechanized assembly } \\
\text { 2.1. Injury by using of temporary elements by oscillating }\end{array}$ & ++ \\
\hline 2.5. Falling of assembled objects during construction & +++ \\
\hline 2.11 Injury by hammering, metal fragments etc
\end{tabular}

\section{CASE STUDY}

\subsection{Implementation}

The BIM-based hazard analysis is based on the identified risks resulting from the hazard analysis. The BIM tool "ceapoint desiteMD 1.0.17" is used for the implementation process. The framework contains two components: a 3D building model and the risk database. This approach allows the integration of risk tables throughout the construction method, which is identified as the only object-oriented category. 
Hence, a direct connection between risk and building element is created. The system is tested on a highrise building model (Figure 4).

The model represents an 87 meter high reinforced concrete building comprising 18 standard floors. This model represents the structure of the building, including different types of objects such as slabs, columns and walls.

Due to the similar floor structure, two floors were extracted from the model for demonstration. The two floors will be exported as the Construction-Process-Integration-XML-file (cpiXML). The cpiXMLfile will be imported to ceapoint desiteMD. Out of that, the building objects will be exported to the tablebased format with the following attributes: No, Name, RevitLevelName and cpID. After exporting this database, which includes the attributes mentioned before, the risks will check against the building elements and will automatically assign. The result of this connection is a graphical representation of the selected building element in the 3D building model and the arguments in the output table with the associated risks (Figure 5).

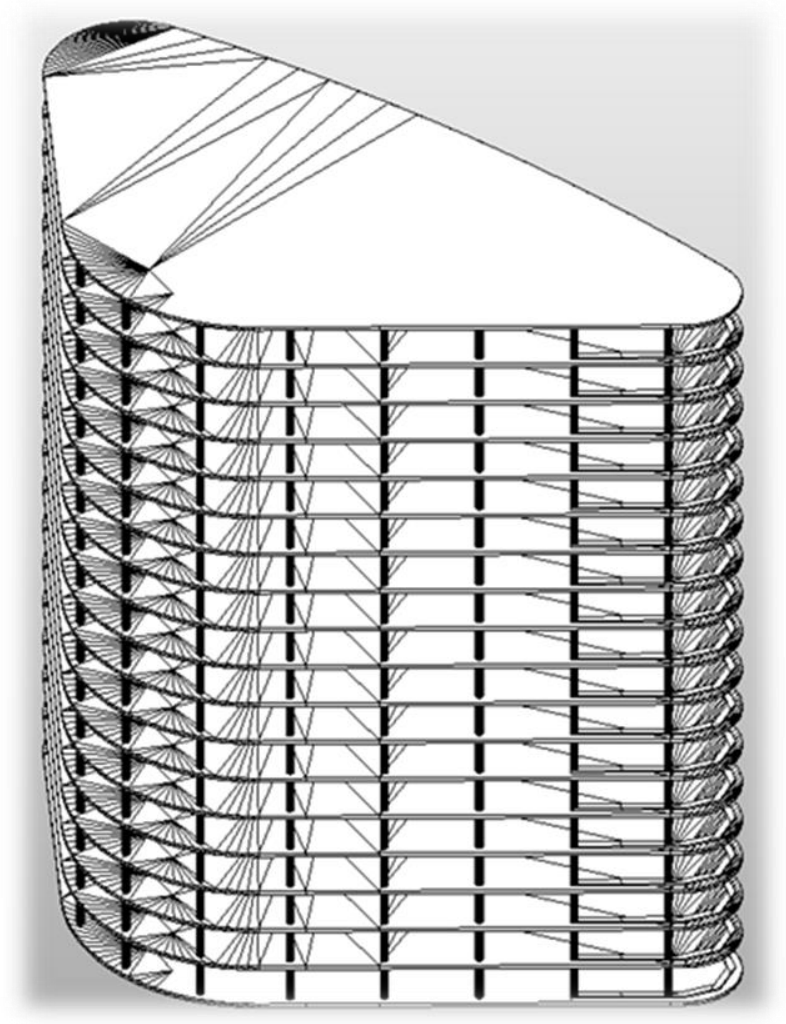

Figure 4: View of the building information model.

\subsection{Results}

The results of the research which are exemplary shown in Figure 5 display a comprehensive objectoriented construction job hazard analysis. By selecting an building object in the model such as a column in Figure 5 in an additional window will displayed all hazard witch can occur based on statistical evaluation. The lists of hazards shed light on the name of object and an unambiguous ID of the object. Furthermore it informs about the default construction method. In this case the assembling of a prefabricated concrete column is selected. Moreover, the type of selected building element and the probability of 
occurrence according to Equation (1) of the associate risk is informed. The results indicate that Job Hazard Analysis can integrated in the BIM processes. The performed research demonstrates flexible and project specific assessment tool for safety planning.
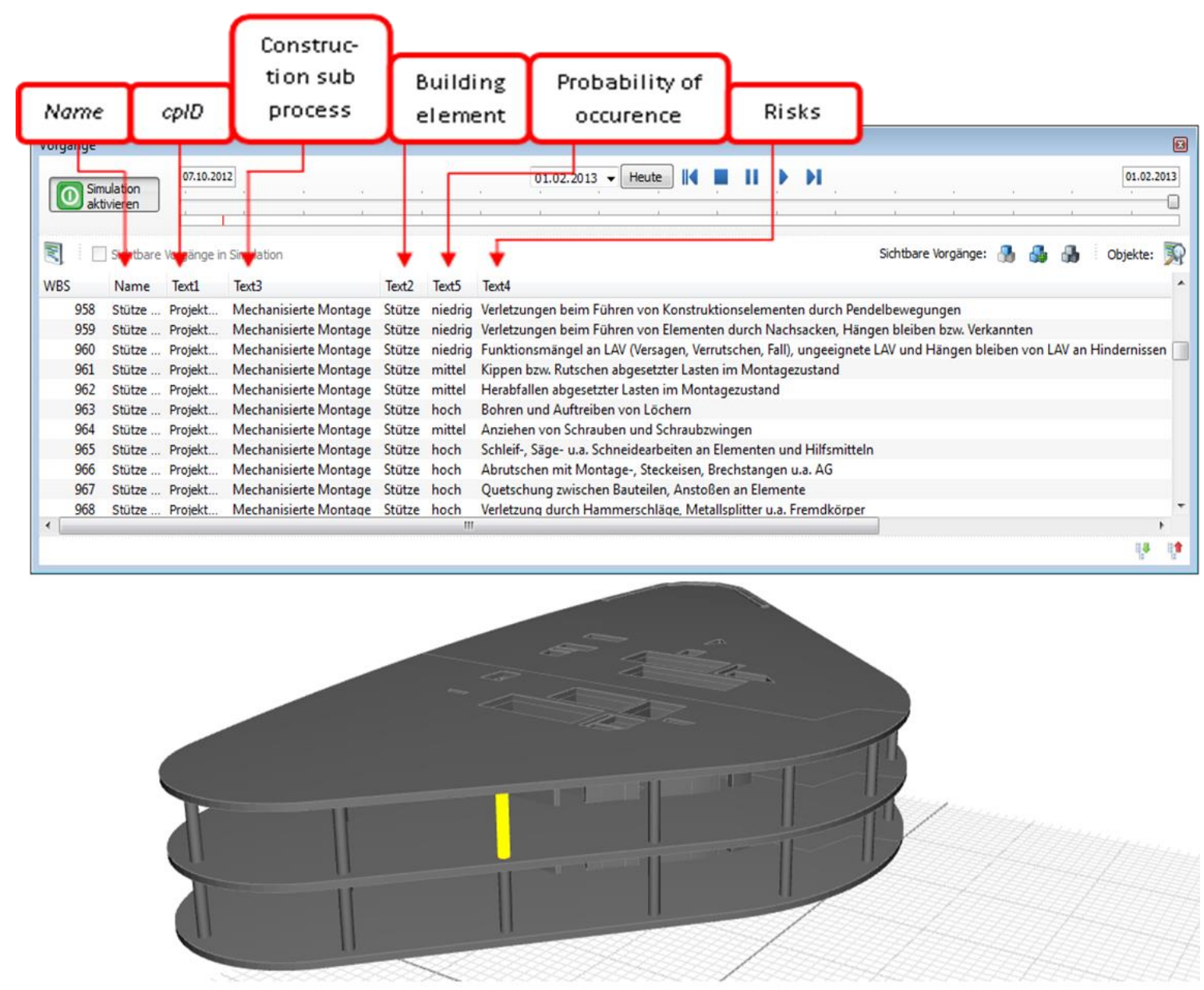

Figure 5: View of 3D building model with selected building element column (below) and associated risks in a table (above).

\section{FUTURE WORK}

In this research, the hazards caused by building geometry and construction environment have not been turned into risks because there are no statistical evaluations. Hence, a different approach must be applied. Since the building geometry is concerned with lines, areas and spatial dimensions, these factors are introduced under three categories: line-related, area-related and spatial-related hazards.

The line-related hazard categories include (Melzner et al. 2012a):

- distance from working area to the building edge,

- distance from working area to the lower level, and

- distance from working area to other objects. 
The area-related hazards include:

- deepening in the floor,

- holes and openings in the floor,

- the area or level itself as work place,

- an inclined slope as work place, and

- changing floor elevations, e.g. from one level to the next level.

The spatial-related hazards include:

- ceiling height and

- atmospheric environment.

The hazards that are caused by the construction environment have neither to do with construction methods nor with building geometry. The construction environment describes the working area in which construction workers do their job or task. The German construction site regulations (BauStellV) deliver the input data in this regard, such as working near high levels of traffic, working close to high-voltage lines or working above (open) water. Future work will include the implementation of the geometric hazards, as mentioned before, to provide a comprehensive job hazard analysis tool.

\section{CONCLUSION}

This research identifies focal points of occupational accidents as well as risks and hazards influencing the safety of construction workers. This paper determines the job hazards related to construction process. After linking such risks to a 3D building model, the results are demonstrated with the commercial BIM software ceapoint desiteMD. The advantage of this approach is that after selecting the building element in the 3D model, the risk table displays the associated risks for the selected object. However, the risk analysis is methodologically limited to the process-driven hazard of building construction. This method, however, does not detect the hazards that may result from geometrical aspects and the construction environment.

This research demonstrates the application of a model-based job safety analysis. The framework supplies the project team with important information about the connection between construction method, building element and the related risks. Future research on this topic may include the expansion to different trades and an evaluation of a real construction safety process.

\section{REFERENCES}

Associated General Contractors of America (AGC). 2010. The Contractors Guide to BIM, Lincoln, NE. Accessed June 22, 2012. www.agcnebuilders.com/documents/BIMGuide.pdf.

AUVA - Allgemeine Unfallversicherungsanstalt. 2011. Anerkannte Arbeitsunfälle im engeren Sinn 2011, Bauwesen, spezifische Tätigkeit, Gegenstand der Spezifischen Tätigkeit.

Benjaoran, V., and S. Bhokha. 2010. An Integrated Safety Management with Construction Management using 4D CAD Model. Safety Science 48(3): 395-403.

Cooke, T., H. Lingard, N. Blismas, and A. Stranieri. 2008. "ToolSHeDTM: The Development and Evaluation of a Decision Support Tool for Health and Safety in Construction Design". Engineering, Construction and Architectural Management 15(4): 336-351.

DGUV - Deutsche Gesetzliche Unfallversicherung. 2010. Arbeitsunfallgeschehen 2010: Statistik Makrodaten, Arbeits- und Schülerunfälle.

Fisher, J. W., and J. H. A. Struik. 1974. Guide to Design Criteria for Bolted and Riveted Joints, Wiley, New York.

Gambatese, J., J.W. Hinze, and C.T. Haas. 1997. "Tool to Design for Construction Worker Safety." In: Journal of Architectural Engineering 3(1): 32. 
Hadikusumo, B.H.W., and S. Rowlinson. 2002. "Integration of Virtually Real Construction Model and Design-For-Safety-Process Database." Automation in Construction 11 (5): 501-509.

Hartmann, T., J. Gao, and M. Fischer. 2008. "Areas of Application for 3D and 4D Models on Construction Projects." Journal of Construction Engineering and Management 134(10):776-785.

Hecker, S., J. Gambatese, and M. Weinstein. 2004. "Life Cycle Safety: An Intervention to Improve Construction Worker Safety and Health Through Design." In Proceedings of the Designing for Safety and Health in Construction Research and Practice Symposium, Eugene, OR: University of Oregon Press: 212-233.

Kim, H., and H. Ahn. 2011. "Temporary Facility Planning of a Construction Project Using BIM (Building Information Modeling)." In Proceedings of the 2011 ASCE International Workshop on Computing in Civil Engineering: 698-705.

Melzner, J., and H.-J. Bargstädt. 2012a. "BIM-based Job Hazard Analysis.” In: Proceedings of the 12th International Conference on Construction Applications of Virtual Reality, National Taiwan University Press, Taipei, Taiwan.

Melzner, J., S. Zhang, J. Teizer, S. Hollermann, and H.-J. Bargstädt. 2012b. "Safety Planning Based on an Object-Oriented Building Model." In Proceedings of the EG-ICE Conference 2012, Munich, Germany.

Qi, J., R.R. Issa, J.W. Hinze, and S. Olbina. 2011. "Integration of Safety in Design Through the Use of Building Information Modeling." In Proceedings of the 2011 ASCE International Workshop on Computing in Civil Engineering 698-705.

Rozenfeld, O., R. Sacks, Y. Rosenfeld, and H. Baum. 2010. "Construction Job Safety Analysis.” Safety Science 48:491-498.

Röbenack, K. D., and B. Nowak. 1993. Unfallauswertungen im Bauwesen: Untersuchungsergebnisse aus Bauunternehmungen Sachsens, Sachsen-Anhalts und Thüringens für den Zeitraum 1970 bis 1988. Dortmund, Bremerhaven. Bundesanstalt für Arbeitsschutz; Wirtschaftsverlag NW.

Schüler, T. 2011. Ermittlung von Ursachenfaktoren für Arbeitsunfälle innerhalb bautechnologischer Linien sowie auf Gebieten mit Querschnittscharakter und Ableitung von Präventionsmaßnahmen. Dissertation. Weimar.

Sulankivi, K., T. Mäkelä, and M. Kiviniemi. 2009. "Tietomalli ja työmaan turvallisuus. Tutkimusraportti VTT-R-01003-09.“ Available online: http://www/inf/julkaisut/muut/2009/turvabim.pdf.

Sulankivi, K., K. Kähkönen, T. Mäkelä, and M. Kiviniemi. 2010. “4D-BIM for Construction Safety Planning." In: Proceedings of the CIB 2010 World Congress. Manchester, UK.

U.S. Dept. of Labor. 2002. Job Hazard Analysis. Publication 3071, Occupational Safety and Health Administration, Washington, DC.

WorkCover. (2001). "CHAIR Safety in Design Tool." New South Wales, Australia, http://www.workcover.nsw.gov.au/formspublications/publications/Documents/chair_safety_in_desig n_tool_0976.pdf

Zhang, S., J. Teizer, J.-K. Lee, C.M. Eastman, and M. Venugopal. 2013. "Building Information Modeling (BIM) and Safety: Automatic Safety Checking of Construction Models and Schedules." Automation in Construction 29:183-195.

\section{AUTHOR BIOGRAPHIES}

JÜRGEN MELZNER is an civil engineer in the Institute of construction engineering and management, Bauhaus-University Weimar. He received an engineering degree from the Georg-Simon-Ohm University of Applied Sciences Nuremberg, Germany and a master degree in business administration (MBA). Before moving to academia, he accumulated several years of construction site management experience for turnkey construction. He is doing his dissertation in construction management. His email address is juergen.melzner@uni-weimar.de. 
SEBASTIAN HOLLERMANN is an civil engineer in the Institute of construction engineering and management, Bauhaus-University Weimar. He is doing his dissertation in construction management. Before moving to academia, he accumulated several years of construction site management experience for bridges at Bilfinger Berger Ingenieurbau GmbH, Scandinavian Branch, Göteborg, Sweden, Awarding authority for bridges with subsidence caused by mining, Water and Shipping Administration of the Federal Republic of Germany, Hamm, Germany. He received an engineering degree from the University of Applied Sciences Münster, Germany, a Scholarship of German National Academic Foundation, a journeyman's certificate of the Chamber of Crafts, Vechta, Germany, and a research grant of the German Academic Exchange Service for a research about shear connectors for timber concrete composite bridge constructions, Joensuu, Finland. His research interests are in construction process simulation of concrete bridge superstructure building based on significant day-to-day data including costs. His email address is sebastian.hollermann@uni-weimar.de.

SILVIA KIRCHNER was master student at the Bauhaus-University Weimar. She studied real estate and facility management in Mittweida and Built Environment at Napier University Edinburgh. She got her Master degree in Management for construction, real estate and infrastructure at Bauhaus-University Weimar. Her email address is silviakirchner.sk@googlemail.com.

HANS-JOACHIM BARGSTÄDT is Professor for Construction Engineering and Management at the Bauhaus-University Weimar. He studied in Braunschweig, Atlanta and Marseille. He got his Ph. D. from the Technical University Braunschweig in 1988. He worked 3 years in structural engineering offices. After his $\mathrm{Ph}$. D. he worked more than 10 years for an international construction company. There he was responsible site engineer, site manager and project manager for several projects. As branch manager and director of a branch office he managed many different projects as dry docks, harbor construction and bridges as well as hotel and office buildings, and construction in the built environment. Since 2000 he is Professor at the Bauhaus-University Weimar. His research fields are construction processes, construction management, simulation in construction, construction in the built environment and lifecycle considerations. E-mail is hans-joachim.bargstaedt@uni-weimar.de. 